This item was submitted to Loughborough's Research Repository by the author.

Items in Figshare are protected by copyright, with all rights reserved, unless otherwise indicated.

\title{
Free-standing compact cathodes for high volumetric and gravimetric capacity Li-S batteries
}

PLEASE CITE THE PUBLISHED VERSION

https://doi.org/10.1039/C7TA06781J

\section{PUBLISHER}

(c) Royal Society of Chemistry

\section{VERSION}

AM (Accepted Manuscript)

\section{PUBLISHER STATEMENT}

This work is made available according to the conditions of the Creative Commons Attribution-NonCommercialNoDerivatives 4.0 International (CC BY-NC-ND 4.0) licence. Full details of this licence are available at: https://creativecommons.org/licenses/by-nc-nd/4.0/

\section{LICENCE}

CC BY-NC-ND 4.0

\section{REPOSITORY RECORD}

Hu, Cheng, Caroline Kirk, Joaquin Silvestre-Albero, Francisco Rodriguez-Reinoso, and Mark Biggs. 2017. "Free-standing Compact Cathodes for High Volumetric and Gravimetric Capacity Li-s Batteries". Loughborough University. https://hdl.handle.net/2134/26303. 
Doi: $10.1039 /$ C7TA06781J

\title{
Free-standing compact cathodes for high volumetric and gravimetric capacity Li-S batteries ${ }^{\dagger}$
}

\author{
Cheng $\mathrm{Hu}^{\mathrm{a}}$, Caroline Kirk ${ }^{\mathrm{b}}$, Joaquín Silvestre-Alberoc ${ }^{c}$, Francisco Rodríguez-Reinosoc ${ }^{\mathrm{c}}$ and Mark \\ James Biggs*a,d
}

\begin{abstract}
Free-standing high performance Li-S battery cathodes are currently attracting significant research efforts. Loose macroporous structures have been proposed by many to improve sulfur utilization and areal capacity. However, their low cathode sulfur densities and high electrolyte fractions lead to low cell volumetric and gravimetric capacities. We report here a compact free-standing Li-S cathode structure that delivers areal, volumetric and gravimetric capacities all exceed those of typical Li-ion batteries. The cathodes, formed by pressure filtration of the constituents, are composed of highly micro/mesoporous nitrogen-doped carbon nanospheres (NCNSs) embedded in the macropores of a multi-walled carbon nanotube (MWCNT) network to form a dense structure. The MWCNT network facilitates low cathode impedance. The NCNSs maximize sulfur utilization and immobilization. These collectively result in high cathode volumetric capacity $\left(1106 \mathrm{mAh} \mathrm{cm}^{-}\right.$ ${ }^{3}$ ) and low electrolyte requirement ( $6 \mu \mathrm{L} \mathrm{mg}^{-1}$ of sulfur), which together leads to high cell-level gravimetric capacity. Stable long-term cycling at $0.3 \mathrm{C}\left(2.5 \mathrm{~mA} \mathrm{~cm}{ }^{-2}\right.$ for $5 \mathrm{mg} \mathrm{cm}^{-2}$ areal sulfur-loading) has also been achieved, with the areal and volumetric capacities of the best remaining above typical Li-ion values over 270 cycles and the per-cycle capacity fading being only $0.1 \%$. The facile preparation means significant potential for large scale use.
\end{abstract}

\section{Introduction}

Many are seeking the next step beyond the Li-ion battery to keep pace with the demand for ever-increasing energy storage capabilities in applications ranging from personal electronic devices through to electric vehicles and beyond such as in aerospace and space vehicles. Li-S batteries are amongst the most promising alternatives because of the high theoretical specific capacity of sulfur (1672 $\left.\mathrm{mAh} \mathrm{g}^{-1}\right)$, its natural abundance, and the rapid progress in virtually all aspects of this technology, especially the cathode design. ${ }^{1-6}$

Wide take-up of Li-S batteries has long been hindered by three challenges that are inherent to the system: (a) the electrically insulating nature of sulfur and its final discharge product $\left(\mathrm{Li}_{2} \mathrm{~S}\right)$ causes low sulfur utilization; ${ }^{7}$ (b) the low density of $\mathrm{Li}_{2} \mathrm{~S}$ results in severe volume expansion of the cathode solid phase at discharge; ${ }^{8}$ and (c) dissolution of the intermediate discharge products, lithium polysulfides (LiPSs), in the electrolyte causes the "shuttle effect" and decreased cell efficiency. ${ }^{9-12}$ Whilst various approaches to addressing these issues have been proposed, none have delivered long-life volumetric capacities that are substantially superior to the Liion systems they are meant to replace. ${ }^{1,13}$ This originates from the low density of sulfur, which is inherent to the system, and the loosely packed cathode matrix being used to improve cathode conductivity. Development of compact high-

\footnotetext{
a. School of Science, Loughborough University, Loughborough LE11 3TU, United Kingdom.E-mail:m.biggs@lboro.ac.uk

b. School of Chemistry, University of Edinburgh, Edinburgh, EH9 3FJ, United Kingdom.

c. Laboratorio de Materiales Avanzados, Departamento de Química Inorgánica, Universidad de Alicante, Apartado 99 E-03080, Spain.

d. School of Chemical Engineering, The University of Adelaide, Australia 5005.

$\dagger$ Electronic Supplementary Information (ESI) available: SEM images, UV-vis spectra, cycling data, tables of calculation results. See DOI: 10.1039/x0xx00000x
}

volumetric-capacity sulfur cathodes will open up possibilities for Li-S batteries in space-premium applications such as compact vehicles and personal electronic devices. The low electrolyte fraction associated with such cathodes will also bring in significant improvement in cell gravimetric capacity. ${ }^{14}$

Incorporating sulfur into porous carbon nanoparticles as a major route of cathode design has been shown to enable high sulfur utilization. ${ }^{15-24}$ It is also evident from the literature that cathodes based on densely packed carbon nanoparticles are able to deliver high volumetric capacities. ${ }^{1}$ Porous carbon nanoparticles also offer the feasibility of heteroatom ( $\mathrm{N}$ and others) doping, which improves LiPSs immobilization and ensures long-term retention of cell efficiency. ${ }^{17,}$ 25-27 However, most of these results have been produced using limited cathode thicknesses with low areal sulfur-loadings, 1,28 most likely because of the difficulties in forming thick, crack-free coatings of the nano-sized carbon-sulfur composites on current collectors. ${ }^{29}$ This in turn leads to areal capacities substantially lower than the Li-ion case $\left(\sim 4 \mathrm{mAh} \mathrm{cm}^{-2}\right)$, making them unsuitable for commercial use. ${ }^{1,28}$

Free-standing three dimensional (3D) carbonaceous networks formed by multi-walled carbon nanotubes (MWCNT), carbon nanofibers (CNF) or graphene have recently been demonstrated as sulfur hosts that are able to achieve high areal sulfur-loadings and areal capacities greater than those of typical Li-ion batteries ${ }^{30-38}$. These free-standing cathodes also do not require a conventional aluminium current collector, which typically occupies $5-7 \mathrm{mg} \mathrm{cm}^{-2}$ passive weight ${ }^{1}$. However, owing to the limited porosity internal to MWCNTs, CNFs and graphene, the networks must be engineered to have an open macroporous structure to accommodate sufficient sulfur. This leads to low volumetric capacities and correspondingly high intra-cathode electrolyte volumes (well in excel of $10 \mu \mathrm{L} \mathrm{mg}^{-1}$ of 
S). ${ }^{33}, 34,39$ The gravimetric capacities of such cells are substantially lowered owing to the high density $\left(\sim 1 \mathrm{mg} \mathrm{mL}^{-1}\right)$ of the energy-passive electrolyte. ${ }^{1,28}$

We present here a cathode structure that brings together the best attributes of the two approaches described above so as to yield a cathode structure that delivers amongst the best volumetric and gravimetric capacities in the field to date whilst offering long cycle life and high areal capacities. The cathodes are formed by pressure filtration of a mixture of highly-porous $\mathrm{N}$-doped carbon nanospheres (NCNSs) and MWCNT to create a dense matrix of the former embedded in a network of the latter. The N-doped high porosity and surface area NCNSs host sulfur at exceptional densities whilst maximizing sulfur immobilization and sulfur-carbon contact. The 3D MWCNT networks acts as an excellent free-standing, electrically conducting matrix. The combination of these in a dense matrix means the cathodes yield high sulfur utilization under high cathode sulfur density, simultaneously leading to low electrolyte fraction and, hence, high volumetric and gravimetric capacities.

\section{Materials and Methods}

\subsection{Preparation of Sulfur-loaded NCNS (S-NCNS) Composites}

Poly(furfural alcohol) nanospheres (PFA-NSs) were synthesized using a template-free emulsion polymerization method. 40 PFA-NSs ( $5 \mathrm{~g}$ ) were transferred to an alumina boat that was then placed in the center of a tube furnace (CARBOLITE, UK) for carbonization, activation and nitrogenation. Carbonization was carried out under $500 \mathrm{~mL} \mathrm{~min}$ ${ }^{1}$ flow of Ar. The furnace temperature was ramped to $900^{\circ} \mathrm{C}$ at $1{ }^{\circ} \mathrm{C} \mathrm{min}-1$ and the temperature was held at $210^{\circ} \mathrm{C}, 650^{\circ} \mathrm{C}$ and the final $900{ }^{\circ} \mathrm{C}$ for 2 hours respectively. Following the carbonization, $\mathrm{CO}_{2}$ activation was undertaken at $900{ }^{\circ} \mathrm{C}$ with $1000 \mathrm{~mL} \mathrm{~min}-1$ flow of $\mathrm{CO}_{2}$ for 15 hours to reach $80 \%$ burn-off. At the end of the activation, the temperature was decreased from $900{ }^{\circ} \mathrm{C}$ to $600{ }^{\circ} \mathrm{C}$ at $3{ }^{\circ} \mathrm{C} \mathrm{min}-1$ whilst the samples were purged with $\mathrm{N}_{2}$ at $1000 \mathrm{~mL} \mathrm{~min}{ }^{-1}$. When the furnace reached $600{ }^{\circ} \mathrm{C}, 200 \mathrm{~mL} \mathrm{~min}-1$ ammonia was introduced and the temperature was maintained for 6 hours for the nitrogenation. After cooling naturally to $300{ }^{\circ} \mathrm{C}$ with the $\mathrm{NH}_{3}$ flow maintained and thereafter to room temperature in $1000 \mathrm{~mL} \mathrm{~min}^{-1}$ of $\mathrm{N}_{2}$, the NCNSs was collected and mixed with sulfur at the desired ratios before being heated to $155{ }^{\circ} \mathrm{C}$ at a rate of $1{ }^{\circ} \mathrm{C} \mathrm{min}-1$ and held for 24 hours with the pressure being adjusted to 0.8 bar to obtain the final S-NCNS composites.

\subsection{Preparation of S-NCNS/MWCNT cathodes}

MWCNT (20-40 $\mathrm{nm}$ diameter, TCI UK) was acid treated ${ }^{41}$ and sonicated in water with isopropyl alcohol ( $2 \mathrm{wt} \%$ ) to form a dispersion. The cathodes were formed via $\mathrm{N}_{2}$ driven pressure filtration employing a homemade stainless steel pressure filtering device and porous nylon filter discs. A $1 \mathrm{mg} \mathrm{cm}^{-2}$ thin layer of MWCNT was first formed to serve as the current collector. S-NCNS composites was then mixed with acid-treated MWCNT at weight ratios of 3.75:1, 4.3:1 and 5:1 for S60-NCNS, S65-NCNS and S70-NCNS, respectively and subsequently ballmilled in water with isopropyl alcohol ( $2 \mathrm{wt} \%$ ) for $30 \mathrm{~min}$ to form homogeneous mixtures. The mixtures were then pressured filtered on top of the pre-formed MWCNT layers to form the 3D S-NCNS/MWCNT cathodes. The filtration was driven by $1 \mathrm{MPa}$ of compressed $\mathrm{N}_{2}$. The amount of the mixture used was adjusted to deliver an areal sulfur-loading of $5 \mathrm{mg} \mathrm{cm}^{-2}$ for each SNCNS/MWCNT cathode. At the end of the filtration, $0.1 \mathrm{~g} \mathrm{~mL}^{-1}$ aqueous styrene butadiene rubber solution was brush-coated on to the filtration cake and the free-standing cathodes were peeled off from the filter disc after vacuum drying. The weight of the fabricated cathodes was 12.4, 11.0 and $9.8 \mathrm{mg}$ for S60NCNS, S65-NCNS and S70-NCNS respectively. Cathodes discs with a diameter of $11 \mathrm{~mm}$ were used for the subsequent electrochemical tests.

\subsection{Material Characterization}

Scanning electron microscopy (SEM) was carried out on a JEOL JSM-7800F microscope operating at $5 \mathrm{kV}$. Cathodes in the discharged state were transferred to the instrument using an $\mathrm{Ar}$ atmosphere chamber for imaging. Scanning transmission electron microscopy (STEM) was carried out using a FEI Tecnai F20 field emission gun microscope operating at $200 \mathrm{kV} . \mathrm{N}_{2}$ adsorption and desorption experiments were carried out using a Quadrasorb-Kr/MP apparatus (Quantachrome, USA). Before the adsorption measurement, the sample was degassed at 250 oC for 8 hours under high-vacuum $\left(10^{-4} \mathrm{~Pa}\right)$. Specific surface area was calculated using the Brunauer-Emmett-Teller (BET) model that accounts for the presence of microporosity. ${ }^{42}$ The pore size distribution was calculated using the quenched solid density functional theory (QSDFT) models. ${ }^{43}$ Raman spectroscopy was performed on a Horiba Jobin-Yvon LabRam HR spectrometer with excitation provided by a $514 \mathrm{~nm}$ green laser. X-ray photoelectron Spectroscopy (XPS) was performed on a Thermo Scientific K-Alpha spectrometer with a monochromated Al K $\alpha$ xray source. Survey spectra were collected with an analyzer pass energy of $200 \mathrm{eV}$. High resolution scans of the N1s region were performed with a resolution of $0.1 \mathrm{eV}$ and a low pass energy of $50 \mathrm{eV}$. The collected N1s spectra was baseline-corrected using Shirley functions and deconvoluted using 1:4 LorentzianGaussian mixtures. The deconvolution was performed using the Thermo Avantage software (Thermo Scientific, UK). X-ray diffraction was carried out using a Bruker D8 Advance diffractometer in reflection geometry with $\mathrm{Cu} \mathrm{K} \alpha_{1}$ radiation and a LYNXEYE detector. Diffraction patterns were collected over the $2 \vartheta$ range of $10^{\circ}$ to $100^{\circ}$ at $1^{\circ} \mathrm{min}^{-1}$ with a step size of $0.016^{\circ}$. Thermogravimetric analysis (TGA) was carried out using a Q600 analyzer (TA Instruments, UK). Analysis of samples of approximately $10 \mathrm{mg}$ at a ramping rate of $10{ }^{\circ} \mathrm{C} \mathrm{min}-1$ under a $100 \mathrm{~mL} \mathrm{~min}-1$ flow of $\mathrm{N}_{2}$ was conducted. Solution phase $\mathrm{Li}_{2} \mathrm{~S}_{6}$ adsorption tests were performed following reported procedures. ${ }^{21,27} 50 \mathrm{mg}$ of adsorbent (NCNSs or Super P carbon black) was added to $20 \mathrm{~mL}$ of the $4 \mathrm{mM} \mathrm{Li}_{2} \mathrm{~S}_{6}$ solution and stirred at room temperature for $30 \mathrm{~min}$. The NCNSs and the carbon black were filtered using glass fiber filters and the concentration of the resulting residue solutions was determined by UV-Vis spectrophotometry (Lambda35, Perkin Elmer, USA) using the intensity at $420 \mathrm{~nm}$. Preparation and handling of the $\mathrm{Li}_{2} \mathrm{~S}_{6}$ 
solutions were carried out in an Ar-filled glovebox (LABstar, MBRAUN, Germany).

\subsection{Electrochemical Measurements}

Li-S cells were assembled in CR2032 coin cells in an Ar-filled glovebox (LABstar, MBRAUN, Germany). One layer of Celgard 2325 membrane was used as separator and lithium foils (99.9 $\%$, Alfa Aesar UK, punched to $13 \mathrm{~mm}$ diameter discs) were used as the anodes. The electrolyte was $30 \mu \mathrm{L}$ of $1 \mathrm{M} \mathrm{LiTFSI} \mathrm{plus} 1 \% \mathrm{wt}$ $\mathrm{LiNO}_{3}$ dissolved in 1:1 (v/v) mixture of 1,3-dioxolane $(99.5 \%$ anhydrous) and 1,2-dimethoxyethane (99.9\%, anhydrous). Cyclic voltammetry was carried out on a $\mu A U T O L A B$ potentiostat (METROHM, Switzerland) between $1.6 \mathrm{~V}$ and $2.8 \mathrm{~V}$ at a scan rate of $0.1 \mathrm{mV} \mathrm{s} \mathrm{s}^{-1}$. Electrochemical impedance spectroscopy was performed on a potentiostat/galvanostat (model 263A, Princeton Applied Research, USA) coupled with a frequency response analyser (model 1250, SOLARTRON, USA). The frequency range was $100 \mathrm{kHz}$ to $0.1 \mathrm{~Hz}$ and the perturbation amplitude was $5 \mathrm{mV}$. Galvanostatic charge/discharge measurements were performed on a BTS9000 battery testing system (NEWARE, China). The $\mathrm{C}$ rates were determined based on the amount of sulfur present in the test cells using $1 C=1672$ $\mathrm{mA} \mathrm{g}^{-1}$ of sulfur.

\section{Results and Discussion}

\subsection{Cathode Preparation and Structure}

Cathodes with areal sulfur-loading of $5 \mathrm{mg} \mathrm{cm} \mathrm{cm}^{-2}$ were fabricated and tested. The fabrication route and structure of the cathodes are illustrated in Fig. 1. Poly(furfuryl alcohol) nanospheres (PFA-NS), synthesized using a template-free emulsion polymerization method, ${ }^{40}$ were used as the carbon precursor. The resulting PFA-NS were subjected to carbonization, $\mathrm{CO}_{2}$ activation and $\mathrm{NH}_{3}$ nitrogenation to form the NCNSs. Sulfur was incorporated into the NCNS pores via meltdiffusion to form the S-NCNS composites.

Three S-NCNS composites with different sulfur contents were synthesized; these are denoted Sxx-NCNS, where $x x$ indicates the sulfur fraction in wt\% $(60,65$ and 70$)$. Fig. 1b shows the scanning electron microscopy (SEM) image of S70NCNS. It is clear that the nanospherical morphology of the PFANS (Fig. S1, ESI) is preserved in the sulfur-loaded NCNS composites due to the thermal-setting nature of PFA. Residual sulfur clusters were not observed amongst the spheres, which indicates successful sulfur incorporation into the NCNSs.

The cathodes used in this study were formed via nitrogendriven pressure filtration. A MWCNT aqueous dispersion was first prepared and pressure filtered on the filter disc to form a 1 $\mathrm{mg} \mathrm{cm} \mathrm{cm}^{-2}$ thin layer of MWCNT to serve as the current collecting layer (Fig. 1c). S-NCNSs was then ball-milled with MWCNT in deionized water with isopropyl alcohol (2 wt\%) to form a homogeneous mixture and subsequently filtered on top of the MWCNT layer with $1 \mathrm{MPa}$ positive pressure to form a dense 3D

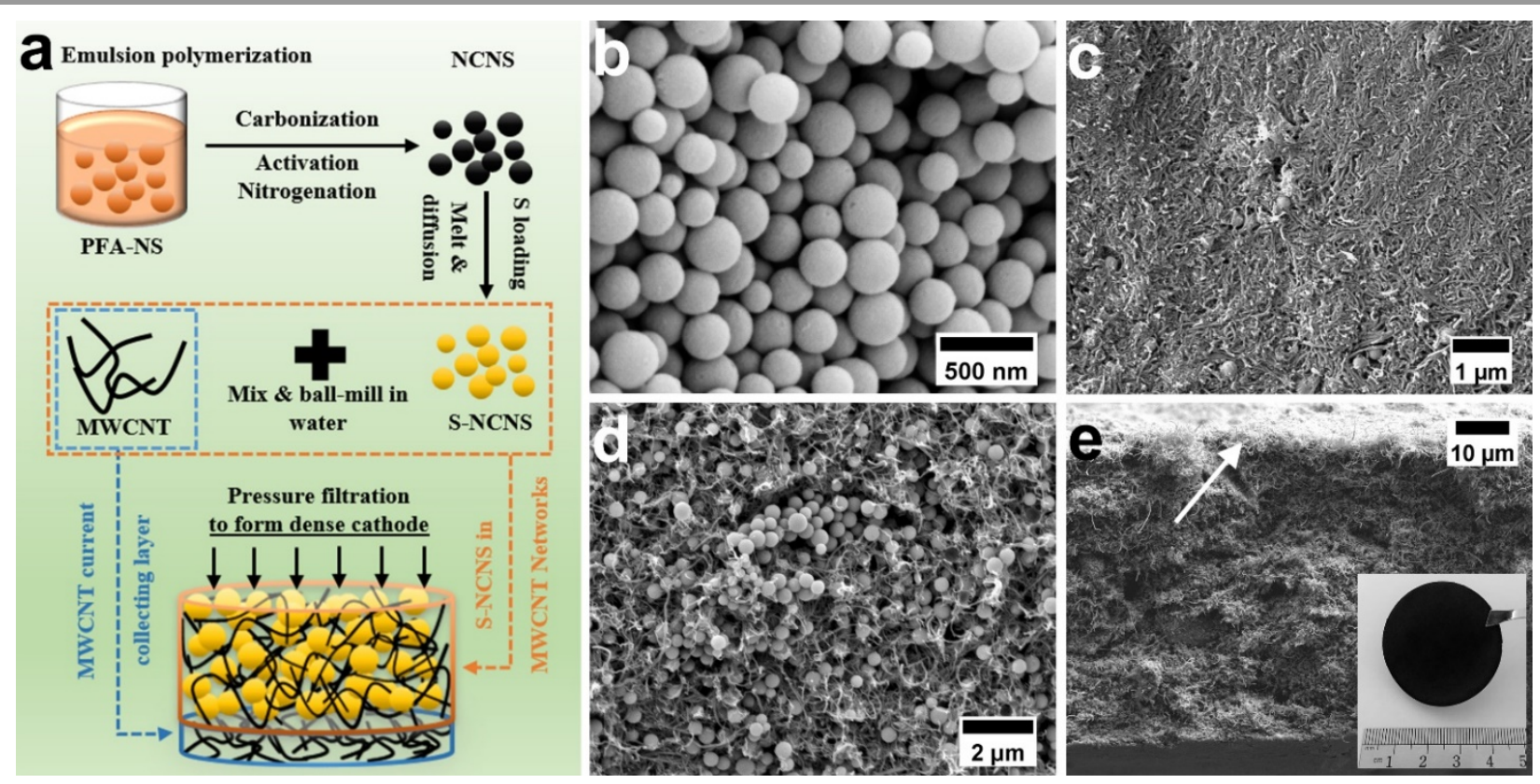

Fig.1 Fabrication and structure of the S-NCNS/MWCNT cathodes: (a) fabrication route of the S-NCNS/MWCNT cathodes; (a) SEM image of the S70-NCNS composite; (b) SEM image of the MWCNT current collecting layer; (c) SEM image of the S70-NCNS/MWCNT structure; and (d) cross-sectional SEM image of a prepared S60-NCNS/MWCNT cathode (A prepared free-standing S-NCNS/MWCNT cathode shown inset). The MWCNT current collecting layer is indicated by arrow in (d). 
S-NCNS/MWCNT structure (Fig. 1d). As seen in Fig. 1d, the SNCNSs are well embedded in the dense cross-linked MWCNT network, whilst sufficient electrolyte diffusion channels around 100-300 $\mathrm{nm}$ in size exist within the S-NCNS/MWCNT structure. Cross-sectional SEM image shown in Fig 1e suggests high packing density and good homogeneity of the S-NCNS/MWCNT structure across the prepared cathode. The MWCNT current collecting layer (indicated by arrow) is also visible in Fig. 1e. At the end of the filtration, aqueous styrene butadiene rubber binder was brush-coated on to the top-surface of the filtration cake. The binder and the robust MWCNT current collecting layer (Fig. 1c) together ensure the structural integrity of large cathodes. The free-standing cathodes were easily peeled off from the filter discs after vacuum drying (inset Fig. 1e).

\subsection{Characterization of NCNSs and S-NCNS Composites}

Immobilization of sulfur in the NCNS host was carefully examined. The porosity of the NCNSs was evaluated by $\mathrm{N}_{2}$ adsorption and desorption at $77 \mathrm{~K}$. Fig. 2a shows the obtained isotherms, which can be classified as Type Ib. ${ }^{44}$ As shown inset to Fig. 2a with relative pressure on logarithmic scale, continuous and rapid $\mathrm{N}_{2}$ uptake happens at low relative pressures up to $10^{-}$ 2 , indicating the existence of abundant micropores. An open knee exists thereafter until a plateau is reached at relative pressure of 0.2 , achieving $900 \mathrm{~mL}(\mathrm{STP}) \mathrm{g}^{-1} \mathrm{~N}_{2}$ uptake. This can be attributed to the presence of significant levels of larger micropores as well as mesopores. The pore size distribution, which was evaluated using quenched solid density functional theory (QSDFT) ${ }^{43}$, is presented in Fig. 2b. The differential pore volume $(d V(d))$ plot suggests the presence of three groups of porosity centered around $0.9,1.5$ and $3.2 \mathrm{~nm}$. The cumulative pore volume $(V(d))$ plot indicates a micropore volume of $1.2 \mathrm{~cm}^{3}$ $\mathrm{g}^{-1}$ out of a total pore volume of $1.7 \mathrm{~cm}^{3} \mathrm{~g}^{-1}$. The BET specific surface area evaluated using a method that accounts for the microporosity ${ }^{42}$ is as high as $3080 \mathrm{~m}^{2} \mathrm{~g}^{-1}$.

X-ray photoelectron spectroscopy (XPS) was conducted to study the chemistry of the NPCS. The XPS survey scan shown in Fig. 2c suggests that the carbon contains $\mathrm{C}, \mathrm{N}$ and $\mathrm{O}$ at compositions of $93 \mathrm{wt} \%, 5.5 \mathrm{wt} \%$ and $1.5 \mathrm{wt} \%$, respectively. The high resolution $\mathrm{N} 1 \mathrm{~s}$ scan and its deconvolution (inset to Fig. 2c) suggests that $\mathrm{N}$ atoms exist as pyridinic (398.4 eV), pyrrolic $(400.5 \mathrm{eV})$, and quaternary (402.5 eV) groups. Pyridinic and pyrrolic $\mathrm{N}$, which together constitute $85 \%$ of the entire nitrogen present, are known to provide enhanced LiPSs immobilization over pristine carbon surfaces due to polar interactions. ${ }^{25,} 26$

The $\mathrm{N}$-doped pore surface, plus the high porosity and large surface area, results in high LiPSs adsorption on the NCNSs, which is illustrated here by the results of a solution phase adsorption test. ${ }^{21,27} \mathrm{Fig} .2 \mathrm{~d}$ shows the color change in a $20 \mathrm{~mL} 4$ $\mathrm{mM} \mathrm{Li} \mathrm{L}_{6}$ solution after the addition of $50 \mathrm{mg}$ of NCNSs and subsequent stirring for $30 \mathrm{~min}$. Super $\mathrm{P}$ carbon black was used as a reference carbon. ${ }^{16,21,27,45}$ The stark color change in the NCNSs case suggests substantially decreased $\mathrm{Li}_{2} \mathrm{~S}_{6}$ concentration due to its uptake by the NCNS carbon whilst little is seen in the case of the Super P carbon. By determining the concentrations of the filtered solutions after the adsorption test (Fig. S2, ESI), the $\mathrm{Li}_{2} \mathrm{~S}_{6}$ adsorption capability of the NCNSs is estimated to be better than $0.2 \mathrm{~g} / \mathrm{g}, 16$ times that of Super P. This high LiPSs adsorptivity of the template-free NCNSs is equivalent to that reported for $\mathrm{N}$-doped mesoporous carbons synthesized using silica templates. ${ }^{21,27}$

The S-NCNS composites were subjected to thermogravimetric analysis (TGA), results for which are shown in Fig. 2e. The sulfur contents of the three S-NCNS composites
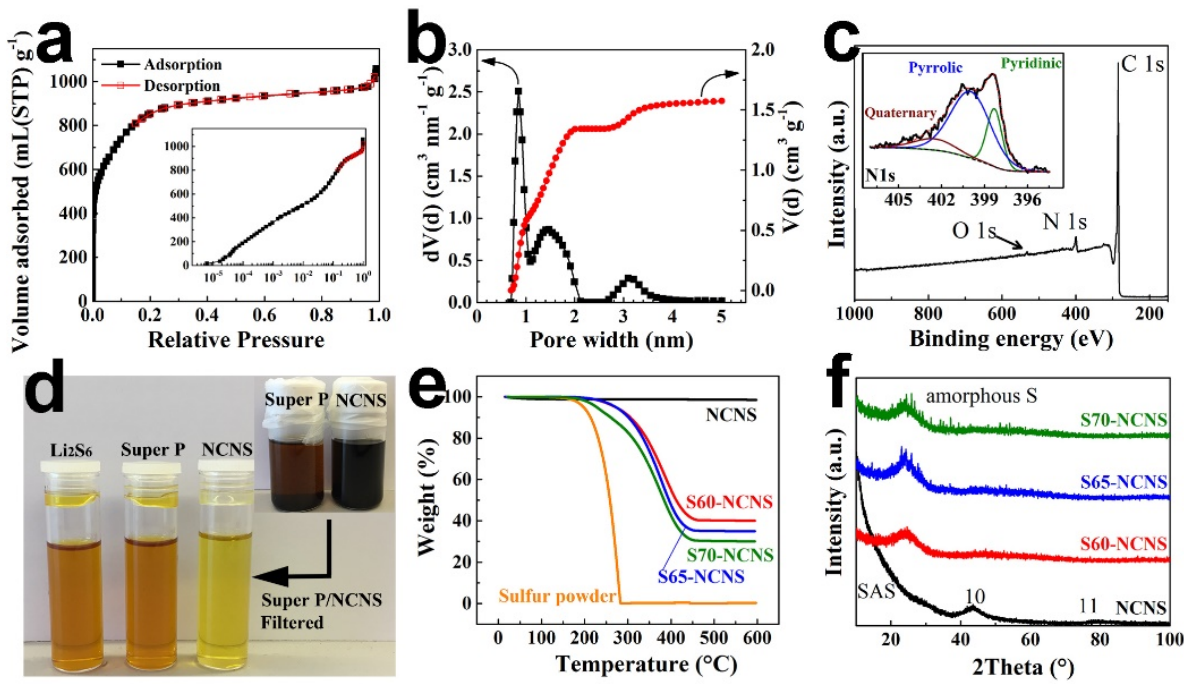

Fig. 2 Structural and chemical characterization of NCNSs and S-NCNS composites: (a) nitrogen adsorption and desorption isotherms of NCNSs on normal and semi-log (inset) scales; (b) pore size distribution of NCNSs; (c) XPS full survey of NCNSs and corresponding high-resolution N1s scan, which is deconvoluted into contributions from pyridinic N (398.4 eV), pyrrolic N (400.5 eV), and quaternary N (402.5 eV); (d) adsorption of Li $2 \mathrm{~S}_{6}$ by the NCNSs and Super P carbon; (e) TGA profiles of NCNSs, the three S-NCNS composites and sulfur powder; and (f) XRD patterns of NCNSs and the three S-NCNS composites. 
were confirmed by the difference between their TGA profiles and that of the NCNSs, which shows little change over the temperature range scanned. Compared with pure sulfur powder (which is also shown, for reference, in Fig. 2e), weight loss due to the evaporation of sulfur from the S-NCNSs takes place at substantially higher temperatures (between $250{ }^{\circ} \mathrm{C}$ and $450{ }^{\circ} \mathrm{C}$ ), which indicates the incorporation of sulfur into the carbon pores. ${ }^{46} \mathrm{Higher}$ weight loss between $250{ }^{\circ} \mathrm{C}$ and $350{ }^{\circ} \mathrm{C}$ was observed for S70-NCNS relative to the other two materials. This can be attributed to the increased sulfur density at the nanosphere peripheries as well as possible small amounts of sulfur that reside on the external surface of the nanospheres.

X-ray diffraction (XRD) was used to identify the phase(s) present in the NCNSs and the S-NCNS composites. The results (Fig. 2f) confirmed all the samples were phase pure. The strong low angle scattering that exists on the NCNSs pattern (high background shoulder at $2 \vartheta \sim 10^{\circ}$ ) disappears for the S-NCNS, indicating occupation of the carbon pores by the incorporated sulfur (whose density is close to that of the carbon skeleton). The one broad peak in the S-NCNS patterns at around $25^{\circ}$ and another more diffuse one at around $45^{\circ}$ are indicative of an absence of long-range ordering of the pore-confined sulfur. ${ }^{22}$

The microstructure of the S-NCNS composite material, S70-
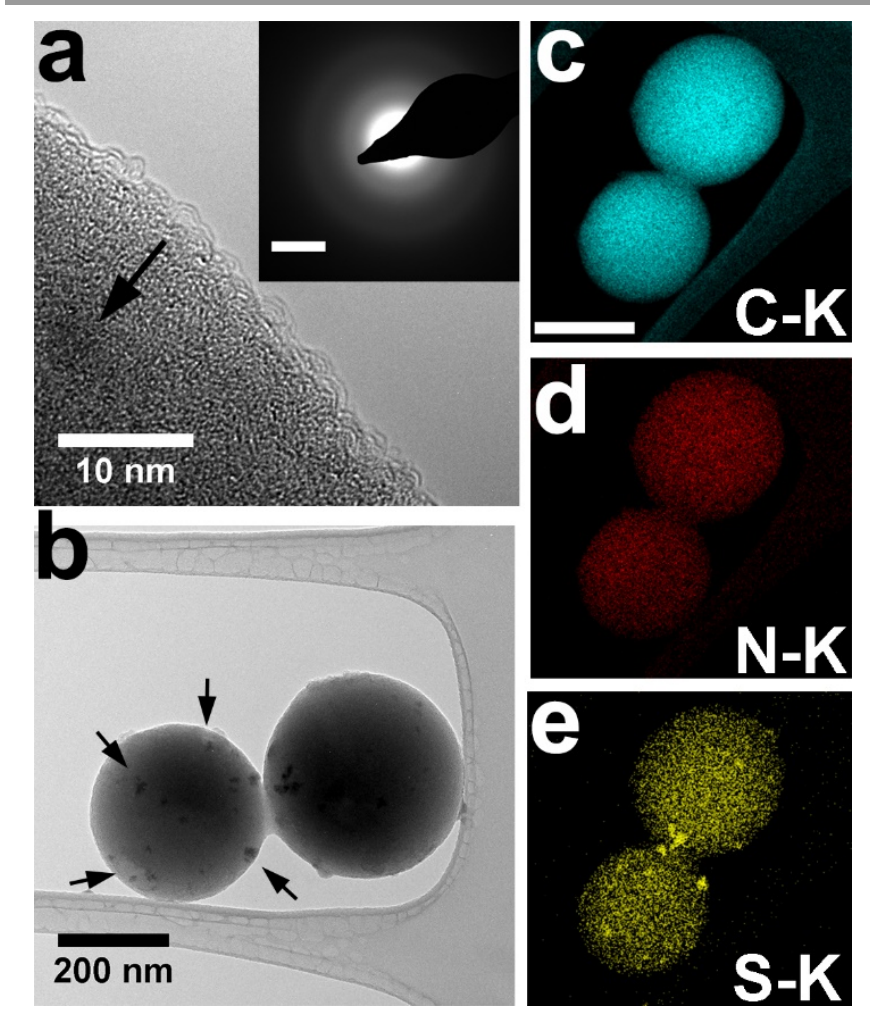

Fig. 3 HRTEM and STEM results of NCNS-S70: (a) high-magnification HRTEM image of the microstructure at the periphery of a nanosphere with the SAED pattern from one of the nanospheres shown inset (scale bar is $5 \mathrm{~nm}^{-1}$ ); (b) low-magnification HRTEM image of two nanospheres; (c) corresponding STEM elemental $C$ mapping in the nanospheres; (d) corresponding STEM elemental $\mathrm{N}$ mapping; and (e) corresponding STEM elemental S mapping. Plates (c-e) share the $200 \mathrm{~nm}$ scale bar of plate (c).
NCNS, was analyzed using scanning transmission electron microscopy (STEM), Fig. 3. Typical non-graphitizing carbon fringes are observed in the high resolution transmission electron microscopy (HRTEM) image (Fig. 3a). The broad Raman $D$ and $G$ bands of the NCNSs (Fig. S3) suggests that the carbon fringes resolved in Fig. 3a are disordered. The curvatures of the fringes can be attributed to the existence of non-hexagonal carbon rings and leads to the formation of the abundant nanopores within the NCNSs. ${ }^{47}$ STEM elemental mapping of carbon, nitrogen and sulfur (Fig. 3c-e, respectively) suggests homogeneous distribution of the three elements within the nanospheres. Local high concentration spots exist on the sulfur mapping, which correlate to the dark spots on the HRTEM images (indicated by arrow in Fig. 3a, b). The high magnification HRTEM image (Fig. 3a) suggests that these sulfur spots are noncrystalline, which is further confirmed by the diffuse rings in the selected area electron diffraction pattern (Fig. 3a inset). They are, therefore, likely due to small amount of randomly distributed non-crystalline sulfur that resides on the external NCNS surface, in-line with the TGA result obtained from this material (Fig. 2e).

\subsection{Cathode Electrochemical Performance}

Compact S-NCNS/MWCNT cathodes with areal sulfurloading of $5 \mathrm{mg} \mathrm{cm}^{-2}$ were fabricated from the three S-NCNS composites and examined. The weight of MWCNT used in each case was the same as that of the NCNSs. The resulting cathode thickness was measured to be 80,65 and $55 \mu \mathrm{m}$ for S60-NCNS, S65-NCNS and S70-NCNS, respectively, whilst the cathode sulfur ratio was calculated to be $43 \mathrm{wt} \%, 48 \mathrm{wt} \%$ and $54 \mathrm{wt} \%$, respectively.

Li-S cells based on the above cathodes were subject to cyclic voltammetry $(\mathrm{CV})$ at a scan rate of $0.1 \mathrm{mV} \mathrm{s}^{-1}$ between $2.8 \mathrm{~V}$ and $1.6 \mathrm{~V}$. The results, which are shown in Fig. $4 \mathrm{a}$, clearly indicate two redox pairs for all three cathodes. The first cathodic peak at around $2.25 \mathrm{~V}$, can be attributed to the reduction of sulfur to soluble long chain LiPSs $\left(\mathrm{Li}_{2} \mathrm{~S}_{x}, 4<x<8\right)$, whilst the second at around $2.0 \mathrm{~V}$ is due to the further reduction of these LiPSs to short chain insoluble sulfides $\left(\mathrm{Li}_{2} \mathrm{~S}_{x}, 1<x<4\right) .{ }^{48} \mathrm{~A}$ broad anodic peak spanning between $2.2 \mathrm{~V}$ to $2.5 \mathrm{~V}$ exists in all the spectra. Close examination indicates that this peak is in fact formed of two closely located anodic peaks that represent the reverse of the cathodic counterparts (i.e. they can be attributed to the continuous pore-confined oxidization of $\mathrm{Li}_{2} \mathrm{~S}$ to LiPSs and, finally, sulfur). ${ }^{48}$ The spectra for the different sulfur-loadings are similar in shape, with the current densities at the cathodic and anodic peaks decreasing marginally with increased sulfur content, which can be attributed to reduced specific sulfur utilization at higher sulfur contents.

Cells based on the three S-NCNS/MWCNT cathodes were also characterized using electrochemical impedance spectroscopy (EIS); the resulting Nyquist plots are shown in Fig. 4b. The EIS was carried out on charged cells after 5 charge/discharge cycles at $0.05 \mathrm{C}$. As the inset to Fig. $4 \mathrm{~b}$ shows, all three spectra contain a single depressed semi-circle ranging 


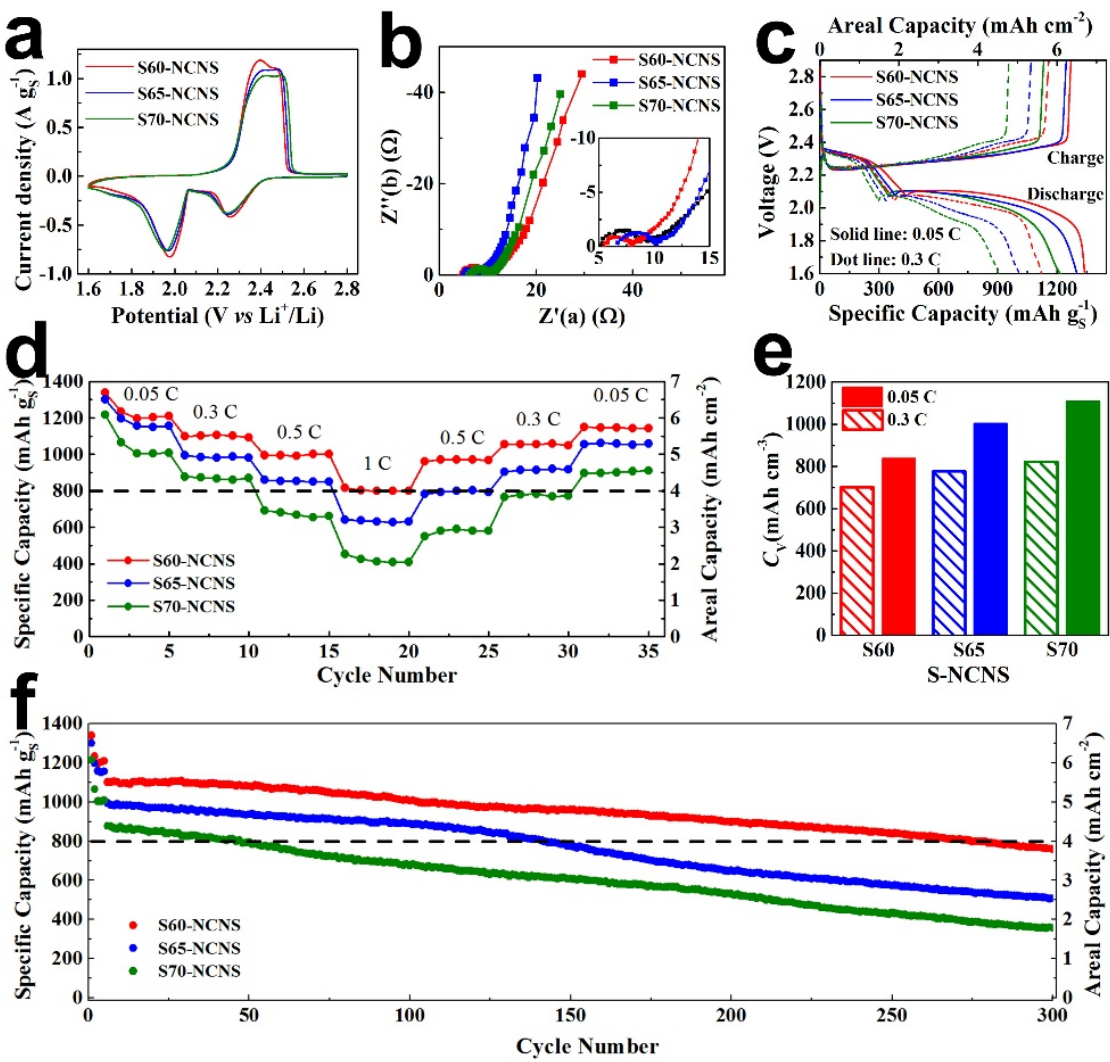

Fig. 4 Electrochemical characterization of the $5 \mathrm{mg} \mathrm{cm}^{-2}$ sulfur-loading S-NCNS/MWCNT cells: (a) cyclic voltammetry profiles; (b) ESI Nyquist plots; (c) firstcycle charge/discharge profiles at $0.05 \mathrm{C}$ and $0.3 \mathrm{C}$; (d) rate performance; (e) cathode volumetric capacities as of first-cycle at $0.05 \mathrm{C}$ and $0.3 \mathrm{C}$; and (f) longterm cycling performance, $0.05 \mathrm{C}$ for 5 cycles and subsequently at $0.3 \mathrm{C}$ up to 300 cycles. $1 \mathrm{C}=1672 \mathrm{~mA} \mathrm{~g}^{-1}$ of sulfur. The typical Li-ion areal capacity (4 mAh $\mathrm{cm}^{-2}$ ) is indicated by dash line in (d) and (f).

from 5 to $10 \Omega$ in the high frequency region, which can be attributed to charge transfer resistance. ${ }^{49}$ The excellent impedance shown here indicates fast charge transport in the compact cathodes and good electrolyte wetting, which can be attributed to the cathode mesostructure of NCNSs embedded in the MWCNT network. The little difference found amongst the three cathodes regardless of the different sulfur contents results from the good confinement of sulfur within the NCNSs.

Galvanostatic charge/discharge was performed for the prepared cells at different $\mathrm{C}$ rates $\left(1 \mathrm{C}=1672 \mathrm{~mA} \mathrm{~g}^{-1}\right.$ of sulfur). Fig. $4 \mathrm{c}$ shows the first cycle results collected at $0.05 \mathrm{C}$ and $0.3 \mathrm{C}$. The charge curves start with a small over-potential of around $2.35 \mathrm{~V}$ before they go on to steadily increase with specific capacity from $2.2 \mathrm{~V}$ to $2.4 \mathrm{~V}$. Besides the variations in sulfur specific capacity, the shape of the charge curves shows little difference amongst the three cathode composites at the two different $C$ rates. The discharge curves exhibit the two usual discharge plateaus. In agreement with the CV profiles, the first at around $2.3 \mathrm{~V}$ correlates to the conversion of sulfur to long chain LiPSs, whilst the second from 2.1 to $2 \mathrm{~V}$ is due to the continued discharge where the long chain LiPSs are converted to $\mathrm{Li}_{2} \mathrm{~S}$.

The second discharge plateau appears to depend on the SNCNS sulfur content as well as the $C$ rate. The increase of $C$ rate or sulfur content clearly leads to a greater drop off in the voltage as discharge proceeds and a softer knee at the end of the discharge. The largest difference is found between S60NCNS cell at $0.05 \mathrm{C}$ and S70-NCNS cell at $0.3 \mathrm{C}$. This can be attributed to the increasing diffusion limitations at either higher sulfur-loadings or higher current densities. A high $1340 \mathrm{mAh} \mathrm{g}^{-1}$ sulfur specific capacity was achieved for the S60-NCNS cell from the initial discharge at $0.05 \mathrm{C}$. This delivers an areal capacity of

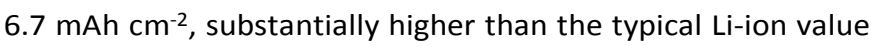
$\left(4 \mathrm{mAh} \mathrm{cm}^{-2}\right.$ ). The discharge specific capacity decreases steadily as sulfur content increases, with the value being $1216 \mathrm{mAh} \mathrm{g}^{-1}$ for the S70-NCNS cathode, offering an areal capacity of $6.0 \mathrm{mAh}$ $\mathrm{cm}^{-2}$. The discharge specific capacities for the first cycle at $0.3 \mathrm{C}$ were $84 \%, 78 \%$ and $74 \%$ of the initial $0.05 \mathrm{C}$ values for the 560 NCNS, S65-NCNS and S70-NCNS cathodes, respectively. At 0.3 $\mathrm{C}$, the areal capacity remained above $4.5 \mathrm{mAh} \mathrm{cm}^{-2}$ for all three cathode composites (Fig. 4c).

The influence of sulfur-loading and $\mathrm{C}$ rate on the specific and areal capacities is further revealed by the rate performance shown in Fig. 4 d. With the $C$ rate being increased from $0.05 \mathrm{C}$ to 1C, a decrease in capacity is visible for all the three S-NCNS cathodes, with the drop being increasing with sulfur-loading. The areal capacity of the S60-NCNS cell at $1 \mathrm{C}$ high rate is enough to match the typical Li-ion value $(4 \mathrm{mAh} \mathrm{cm}-2$, indicated by dash line in Fig. 4d), whilst that of the S65-NCNS and S70NCNS drops below at $1 \mathrm{C}$ and $0.5 \mathrm{C}$, respectively. Good recovery of cell capacity was observed for all cells upon switching the rate back down to lower values. The retention of capacity after the 
rate test (cycle 35 vs cycle 5 in Fig. 4d) was 94.4\%, 91.6\% and $90.2 \%$ for the S60-NCNS, S65-NCNS and S70-NCNS cathodes, respectively, again with a strong dependence on the sulfurloading.

High cathode volumetric capacities were achieved due to the compact cathode structure and the confinement of sulfur in the high porosity and surface area NCNSs. Initial volumetric capacities (Fig. 4e) are evaluated using the data in Fig. 4c along with the cathode thickness data. The highest volumetric capacity obtained here, $1106 \mathrm{mAh} \mathrm{cm}^{-3}$, comes from the S70NCNS cathode operating at $0.05 \mathrm{C}$, the best reported to our knowledge in literature to date and substantially greater than the Li-ion value $\left(500-600 \mathrm{mAh} \mathrm{cm}^{-3}\right) .{ }^{28}$ The volumetric capacity decreases with sulfur content, which can be attributed to the lower sulfur-to-carbon ratios. The same trend is found at $0.3 \mathrm{C}$, although the rate of drop-off with decreasing sulfur content is smaller. This is caused by the larger capacity drop-off at $0.3 \mathrm{C}$ (relative to that of the S60-NCNS cathode) with increasing sulfur content, which leads to higher offsets to the effect of having a smaller cathode volume. Although this is the worst case scenario studied here, the initial volumetric capacity of the S60NCNS cathode at $0.3 \mathrm{C}$ reached $701 \mathrm{mAh} \mathrm{cm}^{-3}$, which is comparable with the best Li-S cathodes reported to date. ${ }^{30,31,50}$

The cells were subjected to long-term cycling at $0.3 \mathrm{C}$ to reach a total of 300 cycles after 5 initial cycles at $0.05 \mathrm{C}$. Fig. $4 \mathrm{f}$ plots the change of sulfur specific capacity and corresponding areal capacity against cycle number. None of the cells failed during the long-term cycling and the two-plateau discharge curve shape was maintained for all cells up to cycle 300 (Fig. S4, ESI). In all cases there was a typical decrease in capacity at cycle 6 due to the switch of $C$ rate from $0.05 C$ to $0.3 \mathrm{C}$. The areal

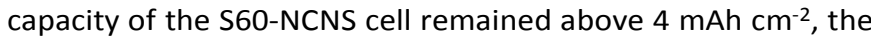
typical Li-ion value, up to 270 cycles, whilst the values for the S65-NCNS and S70-NCNS cells dropped below this at cycle 142 and 46 , respectively. The most stable performance is found with the S60-NCNS cell, with an average capacity fading of $0.1 \%$ per cycle at $0.3 \mathrm{C}$ and $70 \%$ capacity retention after 300 cycles. More rapid capacity fading is found at higher sulfur contents, with the capacity retention after 300 charge/discharge cycles at $0.3 \mathrm{C}$ being $51 \%$ for the $565-$ NCNS cell and $41 \%$ for the S70-NCNS cell.
Calculations ${ }^{50}$ (Table S1, ESI) suggest that the differences in the capacity retention of the three systems considered here can be attributed to the differences in the free volumes within the NCNSs that are available to accommodate the expansion of $\mathrm{Li}_{2} \mathrm{~S}$ as discharge occurs. The free volume available in the S60-NCNS composite is significantly greater than the expected volume expansion accompanying discharge. Enough free volume is also available for S65-NCNS, but there is little margin for the uncertainties that accompany the analysis reflected in Table S1. This analysis clearly demonstrates that the free-volume within the S70-NCNS composite is significantly smaller than the anticipated volume expansion of the solid phase. This leads to the formation of $\mathrm{Li}_{2} \mathrm{~S}$ outside the NCNSs during cell discharge, which results in reduced sulfur utilization and creates stress within the compact cathode structure. The morphology of the cathodes after 100 charge/discharge cycles was examined using SEM. As shown in Fig. 5a, the morphology of the S60-NCNS cathode changes little from the initial uncycled (Fig. 1e) after the 100 charge/discharge cycles. In agreement with Fig. 5a and the calculation in Table S1, cross-sectional SEM imaging of the S60-NCNS cathode in fully discharged state (Fig. 5b) suggests that cathode thickness, uniformity and integrity is well maintained when sulfur is converted to $\mathrm{Li}_{2} \mathrm{~S}$. In vast comparison, the morphology of the S70-NCNS cathode after 100 charge/discharge cycles at $0.3 \mathrm{C}$, Fig. $5 \mathrm{c}$, shows severe localized aggregation and cracking. As discussed above, this can be attributed to the repeated shrinkage and expansion of the cathode volume during cell cycling. The cell separator is seen in Fig. 5c for the S70-NCNS cathode as the formed cracks made its removal impossible without destroying the integrity of the cathode for imaging.

Fig. 6a shows the cathode volumetric capacities calculated from the $25^{\text {th }}, 150^{\text {th }}$ and $300^{\text {th }}$ cycle of the long-term cycling at $0.3 \mathrm{C}$. At cycle 25 , after the initial sharp decline in capacity (Fig. $4 \mathrm{f}$ ), all three cathodes exhibited high volumetric capacities

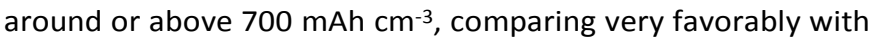
recently published high performance and high sulfur-loading cathodes (Fig. 6b) 14, 30-34, 39, 50-54. For a fair comparison, specific capacities used for calculation are taken from cycle 25, where cells being compared are at 'stable cycling' state. Details of the
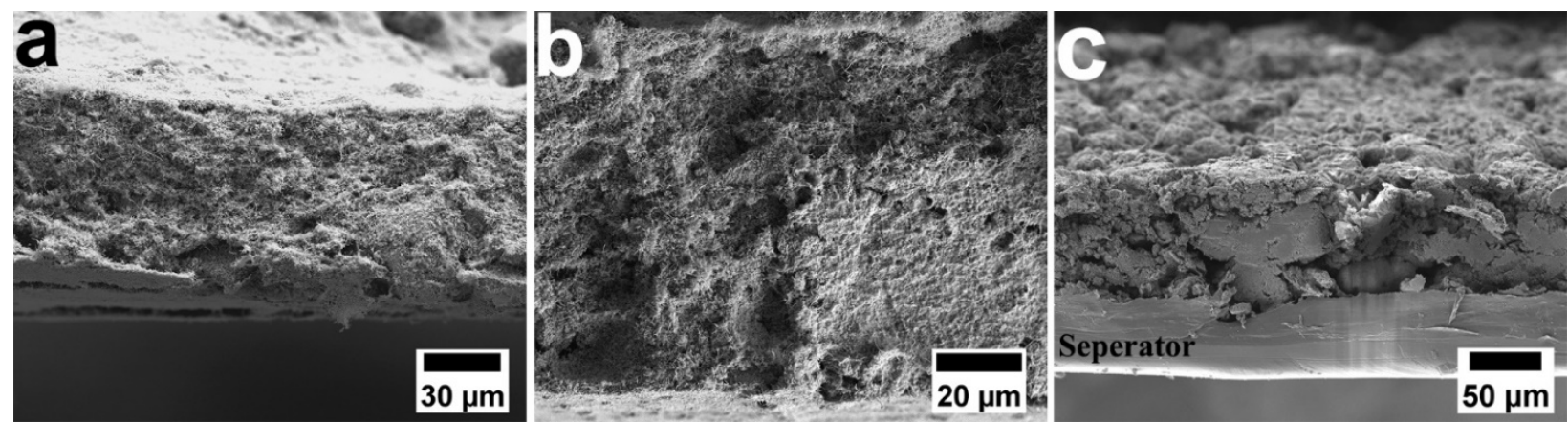

Fig. 5 SEM images of the S-NCNS/MWCNT cathodes after cycling: (a) S60-NCNS cathode after 100 cycles at $0.3 \mathrm{C}$ in charged state; (b) S60-NCNS cathode after 25 cycles at $0.3 \mathrm{C}$ in discharged state; and (c) S70-NCNS cathode after 100 cycles at $0.3 \mathrm{C}$ in charged state. The cell separator is seen in (c) as the damage to the S70-NCNS cathode caused by the cycling made its removal impossible without destroying entirely the integrity of the cathode. 

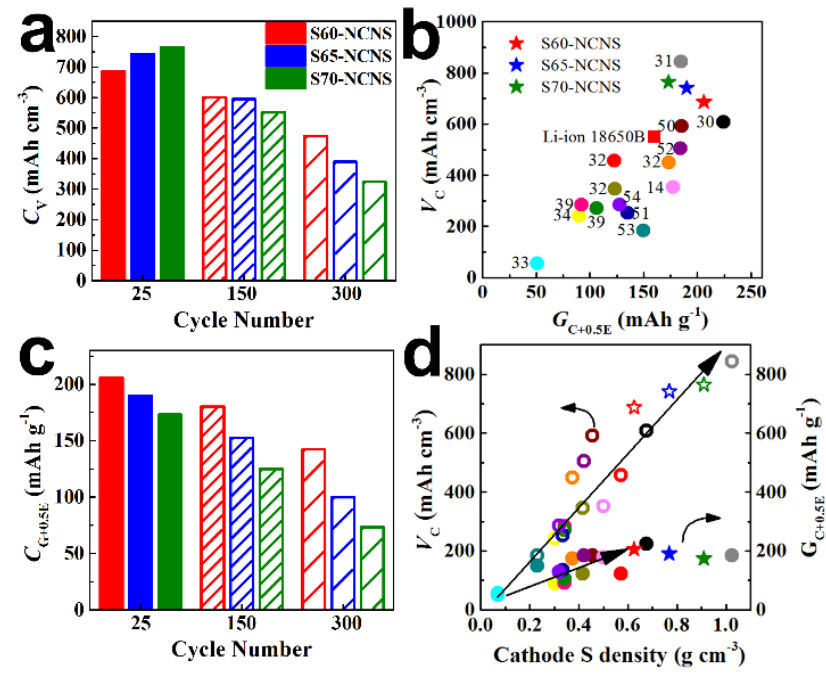

Fig. 6 Volumetric and 'cathode region' gravimetric capacities of the three SNCNS/MWCNT cathodes and the comparison against other recently published results: (a) cathode volumetric capacities of cycle 25, 150 and 300 at $0.3 \mathrm{C}$; (b) cathode volumetric capacity vs 'cathode region' gravimetric capacity for the cathodes considered here (stars), other recently published results (circles with references) and state-of-the-art Panasonic NCR18650B Liion cell; ${ }^{28}$ (c) 'cathode region' gravimetric capacities of cycle 25, 150 and 300 at $0.3 \mathrm{C}$; and (d) 'cathode region' gravimetric capacity (solid symbols) and cathode volumetric capacity (open symbols) vs cathode sulfur density for the cathodes studied here (stars) and other recently published results (circles sharing colors and references in (b)). Data at cycle 25 for $0.3 \mathrm{C}$ are plotted in (b) and (d) for the three S-NCNS/MWCNT cathodes, whilst data at cycle 25 for $0.2 \mathrm{C}$ are shown for the recently published results because they are the most commonly available.

calculations are present in Table S2. The $0.3 \mathrm{C}$ cycling data is used for this study whilst lower $0.2 \mathrm{C}$ data from the published results is used as being most commonly available. The volumetric capacity remained above or comparable with typical Li-ion values $\left(500-600 \mathrm{mAh} \mathrm{cm}^{-3}\right.$, Panasonic NCR18650B ${ }^{28}$ as marked in Fig. 6b) after 150 charge/discharge cycles for all three cathodes here, and after 300 cycles for the S60-NCNS cathode, the best performing cathode studied here.

We also considered the cell gravimetric capacity. Li-S cells require substantially higher electrolyte-to-electrode fractions than Li-ion cells ${ }^{1,28}$. An even higher electrolyte fraction is required for the many 3D cathode structures published to date due to their high open macroporosity (Table S2, ESI). To reflect this and enable comparisons between different cathode structures, we assume that $50 \%$ of the cell electrolyte is held within the 'cathode region' and contributes to the total weight of the 'cathode region'. The 'cathode region' gravimetric capacities $\left(G_{C+0.5 E}\right)$ is therefore able to project the influence of cathode structure on the gravimetric capacity of the entire cell. $G_{C+0.5 E}$ is calculated according to

$G_{C+0.5 E}=\frac{C_{S} \times A_{S}}{\frac{A_{S}}{f_{S}}+0.5 \times C_{S} \times f_{\text {elec }} \times \rho_{\text {elec }}}$

where $C_{S}$ is the specific sulfur capacity $\left(\mathrm{mAh} \mathrm{g}^{-1}\right), A_{S}$ the areal sulfur-loading $\left(\mathrm{mg} \mathrm{cm}^{-2}\right), f_{S}$ the sulfur fraction $(\mathrm{w} / \mathrm{w})$ of the cathode solid phase, $f_{\text {elec }}$ the electrolyte-to-sulfur fraction ( $\mu \mathrm{L}$ $\mathrm{mg}^{-1}$ of S), and $\rho_{\text {elec }}$ the electrolyte density $\left(1 \mathrm{mg}^{\mathrm{L}} \mathrm{L}^{-1}\right)$.

The 'cathode region' gravimetric capacities of cycle 25, 150 and 300 at $0.3 \mathrm{C}$ for the three S-NCNS/MWCNT cathodes are shown in Fig. 6c, and the cycle 25 data is compared with published results in Fig. $6 \mathrm{~d}$. In the case of the published results, 0.2 C cycling data is used, same as the volumetric capacity comparison. Details of the calculations are present in Table S2. All three cathodes studied here are located at the upper end of the comparison range and show higher 'cathode region' gravimetric capacities than the Panasonic NCR18650 Li-ion battery (calculated using data of Hagen et al. ${ }^{28}$ ). The S60-NCNS cathode, in particular, matches the best in the field at cycle 25, and exhibits the best retention over 300 cycles in this study (Fig. 6c), in-line with the sulfur specific capacity data (Fig. 4f).

Further comparison is made in Fig. 6d, where cathode volumetric capacity and the 'cathode region' gravimetric capacity are plotted against cathode sulfur density (sulfur weight divided by cathode volume). The first thing to note here is the cathode sulfur densities obtained here, which are greater than $0.6 \mathrm{~g} \mathrm{~cm}^{-3}$, are amongst the best reported to date. This figure also suggests that the volumetric capacity tends to increase directly with the sulfur density. This reflects the fact that the volumetric capacities obtained here are also amongst the best in the field. It also suggests that the effect of a smaller cathode volume (i.e. more compact cathode structure) can counter the reduced specific sulfur capacity, leading to an improved cathode volumetric capacity.

Unlike the cathode volumetric capacity, Fig. $6 \mathrm{~d}$ suggests that the 'cathode region' gravimetric capacity increases with cathode sulfur density up to $0.6 \mathrm{~g} \mathrm{~cm}^{-3}$ before it plateaus. The increase at lower densities can be attributed to the reducing energy-passive electrolyte associated with a more compact cathode whilst the plateau comes from the sulfur in excess of $0.6 \mathrm{~g} \mathrm{~cm}^{-3}$ being poorly utilized (Fig. 4c). This comparison indicates that $0.6 \mathrm{~g} \mathrm{~cm}^{-3}$ of cathode sulfur density (close to that of the S60-NCNS cathode) could be optimal and offers balanced electrolyte fraction and specific sulfur capacity. This cathode sulfur density converts to around $40 \%$ of voids in the cathode considering the density of sulfur and the carbon skeleton $(\sim 2 \mathrm{~g}$ $\left.\mathrm{cm}^{-3}\right)^{55}$, which ensures good ion diffusion and sufficient voidage into which the lower density discharge products can expand thus avoiding cathode damage.

\section{Conclusion}

We have developed a new Li-S cathode design that sees the embedding of sulfur-loaded, nitrogen doped carbon nanosphere composites (S-NCNSs) into the macropores of a free-standing multi-walled carbon nanotube (MWCNT) network to form a compact structure. In contrast to the open macroporous cathodes proposed by many others in response to the challenges faced by the Li-S technology, the structure developed here allows cathode sulfur densities in excess of 0.6 $\mathrm{g} \mathrm{cm}^{-3}$ and amongst the best volumetric and gravimetric capacities in the Li-S field, substantially higher than those of the state-of-the-art Li-ion battery. The areal capacity achieved is 
also greater than the typical $\mathrm{Li}$-ion value $\left(4 \mathrm{mAh} \mathrm{cm} \mathrm{cm}^{-2}\right)$. Amongst the three S-NCNS composites studied here, the compact cathode based on that containing 60 wt\% of sulfur (S60-NCNS) demonstrates the best capacity retention over cycling: areal and volumetric capacities exceed those typical of Li-ion systems

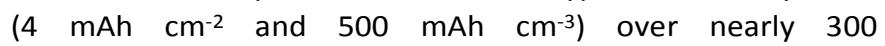
charge/discharge cycles at $0.3 \mathrm{C}$. This excellent performance comes from the combination of the highly micro/mesoporous ( $\leq 4 \mathrm{~nm}$ pore width) N-doped carbon nanospheres (NCNSs) that yields stable high sulfur utilization at high sulfur densities, and the 3D free-standing MWCNT network that ensures good cathode conductivity, impedance and electrolyte ion diffusion in a densely-packed structure. Considering the facile nature of its method of preparation, the sulfur cathodes reported here offer good potential for large scale use.

\section{Conflicts of Interest}

There are no conflicts to declare.

\section{Acknowledgements}

$\mathrm{CH}$ acknowledges a Postdoctoral Fellowship provided by Loughborough University. Dr. Zhaoxia Zhou at Loughborough Materials Characterization Centre, Loughborough University is gratefully acknowledged for assistance with the TEM work.

\section{References}

1 M. A. Pope and I. A. Aksay, Adv. Energy Mater., 2015, 5, 1500124.

2 R. Cao, W. Xu, D. Lv, J. Xiao and J.-G. Zhang, Adv. Energy Mater., 2015, 5, 1402273.

3 S. Zhang, K. Ueno, K. Dokko and M. Watanabe, Adv. Energy Mater., 2015, 5, 1500117.

4 J. G. Wang, K. Y. Xie and B. Q. Wei, Nano Energy, 2015, 15, 413-444.

5 M. Wild, L. O'Neill, T. Zhang, R. Purkayastha, G. Minton, M. Marinescu and G. J. Offer, Energy Environ. Sci., 2015, 8, 3477 3494.

6 Z. Li, H. B. Wu and X. W. Lou, Energy Environ. Sci., 2016, 9, 3061-3070.

7 J. A. Dean, Lange's Handbook of Chemistry, McGraw-Hill, New York, 3rd edn., 1985.

8 X. Ji and L. F. Nazar, J. Mater. Chem., 2010, 20, 9821-9826.

9 R. Xu, I. Belharouak, J. C. M. Li, X. Zhang, I. Bloom and J. Bareño, Adv. Energy Mater., 2013, 3, 833-838.

10 Y. Diao, K. Xie, S. Xiong and X. Hong, J. Electrochem. Soc., 2012, 159, A421-A425.

11 Y. V. Mikhaylik and J. R. Akridge, J. Electrochem. Soc., 2004, 151, A1969-A1976.

12 H. Yamin, A. Gorenshtein, J. Penciner, Y. Sternberg and E. Peled, J. Electrochem. Soc., 1988, 135, 1045-1048.

13 R. Fang, S. Zhao, Z. Sun, D.-W. Wang, H.-M. Cheng and F. Li, Adv. Mater., 2017, DOI: 10.1002/adma.201606823, 1606823.

14 Q. Pang, X. Liang, C. Y. Kwok, J. Kulisch and L. F. Nazar, Adv. Energy Mater., 2017, 7, 1601630.

15 X. Ji, K. T. Lee and L. F. Nazar, Nat. Mater., 2009, 8, 500-506.
16 Y.-J. Li, J.-M. Fan, M.-S. Zheng and Q.-F. Dong, Energy Environ. Sci., 2016, 9, 1998-2004

17 Q. Pang, J. Tang, H. Huang, X. Liang, C. Hart, K. C. Tam and L. F. Nazar, Adv. Mater., 2015, 27, 6021-6028.

18 J. Schuster, G. He, B. Mandlmeier, T. Yim, K. T. Lee, T. Bein and L. F. Nazar, Angew. Chem., Int. Ed., 2012, 51, 3591-3595.

19 G. He, S. Evers, X. Liang, M. Cuisinier, A. Garsuch and L. F. Nazar, ACS Nano, 2013, 7, 10920-10930.

20 S. Niu, G. Zhou, W. Lv, H. Shi, C. Luo, Y. He, B. Li, Q.-H. Yang and F. Kang, Carbon, 2016, 109, 1-6.

21 Q. Sun, B. He, X. Q. Zhang and A. H. Lu, ACS Nano, 2015, 9, 8504-8513.

22 B. Zhang, X. Qin, G. R. Li and X. P. Gao, Energy Environ. Sci., 2010, 3, 1531-1537.

23 Z. Li, Y. Jiang, L. Yuan, Z. Yi, C. Wu, Y. Liu, P. Strasser and Y. Huang, ACS Nano, 2014, 8, 9295-9303.

24 M. Q. Zhao, M. Sedran, Z. Ling, M. R. Lukatskaya, O. Mashtalir, M. Ghidiu, B. Dyatkin, D. J. Tallman, T. Djenizian, M. W. Barsoum and Y. Gogotsi, Angew. Chem., Int. Ed., 2015, 54, 4810-4814.

25 J.-J. Chen, R.-M. Yuan, J.-M. Feng, Q. Zhang, J.-X. Huang, G. Fu, M.-S. Zheng, B. Ren and Q.-F. Dong, Chem. Mater., 2015, 27, 2048-2055.

26 Y. Qiu, W. Li, W. Zhao, G. Li, Y. Hou, M. Liu, L. Zhou, F. Ye, H. Li, Z. Wei, S. Yang, W. Duan, Y. Ye, J. Guo and Y. Zhang, Nano Lett., 2014, 14, 4821-4827.

27 J. Song, M. L. Gordin, T. Xu, S. Chen, Z. Yu, H. Sohn, J. Lu, Y. Ren, Y. Duan and D. Wang, Angew. Chem., Int. Ed., 2015, 54, 4325-4329.

28 M. Hagen, D. Hanselmann, K. Ahlbrecht, R. Maça, D. Gerber and J. Tübke, Adv. Energy Mater., 2015, 5, 1401686.

29 D. Lv, J. Zheng, Q. Li, X. Xie, S. Ferrara, Z. Nie, L. B. Mehdi, N. D. Browning, J.-G. Zhang, G. L. Graff, J. Liu and J. Xiao, Adv. Energy Mater., 2015, 5, 1402290.

30 R. Fang, S. Zhao, P. Hou, M. Cheng, S. Wang, H.-M. Cheng, C. Liu and F. Li, Adv. Mater., 2016, 28, 3374-3382.

31 S.-H. Chung, C.-H. Chang and A. Manthiram, ACS Nano, 2016, 10, 10462-10470.

32 S.-H. Chung, C.-H. Chang and A. Manthiram, Energy Environ. Sci., 2016, 9, 3188-3200.

33 G. Hu, C. Xu, Z. Sun, S. Wang, H.-M. Cheng, F. Li and W. Ren, Adv. Mater., 2016, 28, 1603-1609.

34 L. Qie, C. Zu and A. Manthiram, Adv. Energy Mater., 2016, 6, 1502459.

35 G. Zhou, L. Li, C. Ma, S. Wang, Y. Shi, N. Koratkar, W. Ren, F. Li and H.-M. Cheng, Nano Energy, 2015, 11, 356-365.

36 L. Miao, W. Wang, K. Yuan, Y. Yang and A. Wang, Chem. Commun., 2014, 50, 13231-13234.

37 Z. Li, J. T. Zhang, Y. M. Chen, J. Li and X. W. Lou, Nat. Commun., $2015,6,8850$.

38 K. Jin, X. Zhou, L. Zhang, X. Xin, G. Wang and Z. Liu, J. Phys. Chem. C, 2013, 117, 21112-21119.

39 H. Xu, L. Qie and A. Manthiram, Nano Energy, 2016, 26, 224232.

40 J. Yao, H. Wang, J. Liu, K.-Y. Chan, L. Zhang and N. Xu, Carbon, 2005, 43, 1709-1715. 
41 S. Niu, W. Lv, C. Zhang, Y. Shi, J. Zhao, B. Li, Q.-H. Yang and F. Kang, J. Power Sources, 2015, 295, 182-189.

42 J. Rouquerol, P. Llewellyn and F. Rouquerol, in Stud. Surf. Sci. Catal., eds. P. L. Llewellyn, F. Rodriquez-Reinoso, J. Rouqerol and N. Seaton, Elsevier, Amsterdam and Oxford, 2007, vol. 160, ch. 3, pp. 49-56.

43 A. V. Neimark, Y. Lin, P. I. Ravikovitch and M. Thommes, Carbon, 2009, 47, 1617-1628.

44 M. Thommes, K. Kaneko, V. Neimark Alexander, P. Olivier James, F. Rodriguez-Reinoso, J. Rouquerol and K. S. W. Sing, Pure Appl. Chem., 2015, 87, 1051-1069.

45 C. J. Hart, M. Cuisinier, X. Liang, D. Kundu, A. Garsuch and L. F. Nazar, Chem. Commun., 2015, 51, 2308-2311.

46 Z. Li, L. Yuan, Z. Yi, Y. Sun, Y. Liu, Y. Jiang, Y. Shen, Y. Xin, Z. Zhang and Y. Huang, Adv. Energy Mater., 2014, 4, 1301473.

47 J. Guo, J. R. Morris, Y. Ihm, C. I. Contescu, N. C. Gallego, G. Duscher, S. J. Pennycook and M. F. Chisholm, Small, 2012, 8, 3283-3288.

48 Y. X. Yin, S. Xin, Y. G. Guo and L. J. Wan, Angew. Chem., Int. Ed., 2013, 52, 13186-13200.

49 Z. Deng, Z. Zhang, Y. Lai, J. Liu, J. Li and Y. Liu, J. Electrochem. Soc., 2013, 160, A553-A558.

50 R. Fang, S. Zhao, S. Pei, X. Qian, P.-X. Hou, H.-M. Cheng, C. Liu and F. Li, ACS Nano, 2016, 10, 8676-8682.

51 Q. Pang and L. F. Nazar, ACS Nano, 2016, 10, 4111-4118.

52 H.-J. Peng, W.-T. Xu, L. Zhu, D.-W. Wang, J.-Q. Huang, X.-B. Cheng, Z. Yuan, F. Wei and Q. Zhang, Adv. Funct. Mater., 2016, 26, 6351-6358.

53 Z. Yuan, H.-J. Peng, J.-Q. Huang, X.-Y. Liu, D.-W. Wang, X.-B. Cheng and Q. Zhang, Adv. Funct. Mater., 2014, 24, 6105-6112.

54 L. Qie and A. Manthiram, Adv. Mater., 2015, 27, 1694-1700.

55 C. Hu, S. Sedghi, A. Silvestre-Albero, G. G. Andersson, A. Sharma, P. Pendleton, F. Rodríguez-Reinoso, K. Kaneko and M. J. Biggs, Carbon, 2015, 85, 147-158. 